\title{
Strategies for renal and visceral protection in thoracoabdominal aortic surgery
}

Joseph S. Coselli, MD

The complexity of thoracoabdominal aortic aneurysm (TAAA) repair has long been established. In the earliest days of aortic repair, various techniques were tried in the hope of minimizing ischemic damage to downstream organs. These techniques included decreasing the duration of aortic and visceral artery clamping times with an approach that focused on restoring the renal arteries first, and working backward to complete the aortic repair, using passive shunts to maintain an oxygenated blood supply, and inducing hypothermia to reduce metabolic demand. ${ }^{1,2}$ Nonetheless, in the modern era, renal and visceral ischemia remain lifethreatening complications of TAAA repair. ${ }^{3}$

\section{COLD CRYSTALLOID RENAL PERFUSION}

At our clinic, our approach has been to provide cold crystalloid renal perfusion whenever possible, and to selectively perfuse the celiac axis and superior mesenteric arteries as part of our multimodal approach to TAAA repair, which is guided by the Crawford extent of repair as described elsewhere. ${ }^{4}$ This approach includes moderate systemic heparinization, permissive mild hypothermia $\left(32^{\circ} \mathrm{C}-34^{\circ} \mathrm{C}\right)$, and multiple adjuncts for avoiding spinal cord ischemic injury.

Cold crystalloid (lactated Ringer solution) renal perfusion during TAAA repair has been used since the $1970 \mathrm{~s} .{ }^{5-7}$ Its use does not depend on the concurrent use of left heart bypass (LHB), which is typically limited to more extensive extent I and II TAAA repairs and may be delivered through a separate perfusion circuit in all extents of TAAA repair. Thus in our day-to-day practice, renal perfusion is generally used whenever surgical exposure of the renal ostia is sufficient.

After the origins of the renal arteries are exposed, 9F balloon perfusion catheters are inserted and used to deliver cold $\left(4^{\circ} \mathrm{C}\right)$ crystalloid fluid from a cardiotomy reservoir with $1 / 4$ inch tubing threaded through a roller-head pump. An initial bolus of 400 to $600 \mathrm{~mL}$ of cold crystalloid solution is

\footnotetext{
From the Division of Cardiothoracic Surgery, Michael E. DeBakey Department of Surgery, Baylor College of Medicine, and The Texas Heart Institute at St. Luke's Episcopal Hospital, Houston, Tex.

Disclosures: Joseph S. Coselli is a consultant for Vascutek Terumo and Edwards Lifesciences; is a member of the speakers bureau for Gore \& Associates, Inc; receives grant/research support from Vascutek Terumo, St. Jude Medical, Cook, Inc, and Medtronic, Inc; and receives royalties from Vascutek Terumo for the Coselli Branched TAAA graft.

Received for publication April 28, 2010; accepted for publication July 12, 2010.

Address for reprints: Joseph S. Coselli, MD, One Baylor Plaza, BCM 390, Houston, TX 77030 (E-mail: jcoselli@bcm.edu).

J Thorac Cardiovasc Surg 2010;140:S147-9

$0022-5223 / \$ 36.00$

Copyright (C) 2010 by The American Association for Thoracic Surgery

doi:10.1016/j.jtcvs.2010.07.038
}

instilled in the renal arteries, followed by intermittent infusions of 200 to $300 \mathrm{~mL}$ every several minutes until arterial flow has been reestablished.

Our large clinical practice has provided us with unique opportunities to conduct randomized clinical trials regarding renal perfusion. In one such trial, we compared 2 commonly used renal perfusates: cold crystalloid fluid and isothermic blood. Our analysis showed that patients who received intermittent cold crystalloid perfusion had a significantly lower incidence of postoperative renal dysfunction than did patients who received continuous isothermic blood perfusion. On multivariable analysis, cold crystalloid perfusion was found to be independently protective against acute renal dysfunction. $^{8}$

Recently, we attempted to determine whether cold blood could offer even better renal protection than cold crystalloid fluid. Patients were randomly assigned to receive either cold blood from the LHB circuit or cold crystalloid fluid from a separate circuit. Satisfactory levels of renal hypothermia were achieved in all cases, and the degree of hypothermia achieved did not affect renal outcome. In each group, only a few patients (3\% each) had renal failure that necessitated hemodialysis, and there were no differences in urinary biomarkers of subclinical renal injury. In addition, the incidence of early death did not differ significantly between the cold blood $(8 \%)$ and cold crystalloid $(6 \%)$ groups $(P=.8){ }^{9}$

Although this randomized trial did not support our hypothesis that cold blood would provide better renal protection than cold crystalloid fluid, it did confirm that using cold renal perfusion during TAAA repair provides effective protection against renal injury. We remain proponents of cold crystalloid renal perfusion, which is easier to use and can routinely be applied to greater numbers of patients with TAAA than perfusion with hypothermic or normothermic blood.

At present, it is not clear how commonly cold renal perfusion is used during TAAA repair. Several centers have reported that cold crystalloid fluid, cold saline solution, cold blood, and other cold electrolyte solutions provide effective renal protection. ${ }^{8-12}$ Recent guidelines endorse the consideration of cold crystalloid or cold blood renal perfusion (class IIb, level of evidence B) but do not address other substrates. ${ }^{13}$ Further study may identify additional substrates for cold renal protection during TAAA repair. The need for protective renal perfusion will probably remain high, because many patients with TAAA have preexisting renal dysfunction, which has clearly been associated with early death and morbidity. 


\section{SELECTIVE VISCERAL PERFUSION}

Although LHB is the primary means of providing distal aortic perfusion during TAAA repair, it is used sparingly and is generally limited to Crawford extents I and II. ${ }^{14}$ Also, LHB is used early in the repair, during the proximal anastomosis, and is usually discontinued for the visceral artery reconstruction portion of the repair. To extend the benefits of providing oxygenated blood to the viscera while distal anastomoses are being performed, the LHB circuit may be rerouted by incorporating $9 \mathrm{~F}$ balloon perfusion catheters into a Y-line from the arterial perfusion line of the LHB circuit. These catheters are then placed, under direct vision, into the ostia of the celiac axis and superior mesenteric arteries, where they provide continuous, controlled flow at low volumes. The balloon catheters may provide additional protection by preventing atherosclerotic debris from entering the cannulated arteries or by minimizing active bleeding from these arteries. ${ }^{15}$

Although there is scant evidence to support the use of direct visceral perfusion, ${ }^{13}$ shunts have long been used in TAAA repair, and some clinicians still enthusiastically support their use. ${ }^{16}$ Balloon perfusion catheters may have advantages relative to passive shunts, because the flow rate of blood is better controlled. A potential disadvantage of using balloon catheters is the possibility of perforating or rupturing the vessel during use; however, we have found this risk to be low. Because using these perfusion catheters adds little time to the overall repair and may help prevent such dreaded complications as mesenteric ischemia, postoperative coagulopathy, and bacterial translocation, we continue to use this technique selectively in extents of repair in which the origins of the visceral arteries are exposed.

\section{ADDITIONAL TECHNIQUES TO ENHANCE VISCERAL PERFUSION}

Not uncommonly, visceral arteries are replaced with bypass grafts, or other methods are used to improve their blood-carrying capacity, such as endarterectomy or the use of balloon expandable stents. ${ }^{17}$ Before Crawford's reassessment of the renal first approach, ${ }^{18,19}$ visceral arteries were routinely reattached as individual graft branches, rather than as part of the visceral patch that is commonly used today. Currently, small-diameter Dacron polyester fabric grafts (and, rarely, reversed saphenous veins) are used as needed to replace visceral arteries, particularly the left renal artery because it tends to be somewhat separated from the other visceral branches.

Likewise, endarterectomy has been used since the 1950 s to remove atherosclerotic material near vessel ostia, but endarterectomy also removes a portion of the aortic wall, thinning it. Working under Crawford, we found that renal endarterectomy significantly improved renal outcomes in patients with preoperative renal dysfunction. ${ }^{7}$
Visceral stents are a relatively new addition to the surgeon's $\operatorname{armamentarium}^{17,20}$ and are helpful in treating occlusive disease, obliterating the false lumen in cases of dissection, and preventing kinking in graft branches. Visceral stents may also secure intimal end points after endarterectomy, maintain patent ostia near the patch anastomosis, and facilitate the safe use of perfusion catheters.

Although the previously mentioned techniques are generally considered safe and effective, their potential drawbacks include a friable endarterectomized vessel wall that is difficult to manipulate safely, the additional operative time required to complete individual branch anastomoses, possible perforation of the vessel by the stent, stent migration, and the risk of thrombosis in a branch vessel. ${ }^{17,20,21}$ Currently, we use visceral perfusion-enhancing techniques in more than half of our patients with TAAA to treat branch vessel stenosis. Placement of small-diameter bypass grafts is the most commonly used approach.

\section{CONCLUSIONS}

In summary, the aortic surgeon must continue to explore and refine surgical techniques to prevent operative complications, including potentially lethal complications that stem from renal or visceral ischemia during TAAA repair. We remain enthusiastic proponents of cold crystalloid renal perfusion, which is easier to use and can routinely be applied to greater numbers of patients undergoing TAAA repair than perfusion with either hypothermic or normothermic blood. Also, further study may identify better renal or visceral perfusion strategies, as well as any patient-specific therapeutic limits of such strategies, and enable continued reductions in mortality and morbidity to ensure optimal outcomes for individual patients with TAAA.

\section{References}

1. Chamberlain JM. The use of shunts in surgery of the thoracic aorta. Trans Am Coll Cardiol. 1955;5:176-91.

2. Creech O Jr, DeBakey ME, Morris GC Jr. Aneurysm of thoracoabdominal aorta involving the celiac, superior mesenteric, and renal arteries; report of four cases treated by resection and homograft replacement. Ann Surg. 1956;144:549-73.

3. Coselli JS, Bozinovski J, LeMaire SA. Open surgical repair of 2286 thoracoabdominal aortic aneurysms. Ann Thorac Surg. 2007;83:S862-4;discussion S890-2.

4. Coselli JS, LeMaire SA. Tips for successful outcomes for descending thoracic and thoracoabdominal aortic aneurysm procedures. Semin Vasc Surg. 2008;21:13-20.

5. Crawford ES, Crawford JL, Safi HJ, Coselli JS, Hess KR, Brooks B, et al. Thoracoabdominal aortic aneurysms: preoperative and intraoperative factors determining immediate and long-term results of operations in 605 patients. J Vasc Surg. 1986;3:389-404.

6. Selle JG, Robicsek F, Daugherty HK, Cook JW. Thoracoabdominal aortic aneurysms: a review and current status. Coll Works Cardiopulm Dis. 1979;22:79-90.

7. Svensson LG, Coselli JS, Safi HJ, Hess KR, Crawford ES. Appraisal of adjuncts to prevent acute renal failure after surgery on the thoracic or thoracoabdominal aorta. J Vasc Surg. 1989;10:230-9.

8. Köksoy C, LeMaire SA, Curling PE, Raskin SA, Schmittling ZC, Conklin LD, et al. Renal perfusion during thoracoabdominal aortic operations: cold crystalloid is superior to normothermic blood. Ann Thorac Surg. 2002;73:730-8.

9. LeMaire SA, Jones MM, Conklin LD, Carter SA, Criddell MD, Wang XL, et al. Randomized comparison of cold blood and cold crystalloid renal perfusion for renal protection during thoracoabdominal aortic aneurysm repair. J Vasc Surg. 2009;49:11-9. 
10. Black JH 3rd. Technique for repair of suprarenal and thoracoabdominal aortic aneurysms. J Vasc Surg. 2009;50:936-41.

11. Hassoun HT, Miller CC 3rd, Huynh TT, Estrera AL, Smith JJ, Safi HJ. Cold visceral perfusion improves early survival in patients with acute renal failure after thoracoabdominal aortic aneurysm repair. J Vasc Surg. 2004;39: 506-12.

12. Schepens M, Dossche K, Morshuis W, Heijmen R, van Dongen E, Ter Beek H, et al. Introduction of adjuncts and their influence on changing results in 402 consecutive thoracoabdominal aortic aneurysm repairs. Eur J Cardiothorac Surg. 2004;25:701-7.

13. Hiratzka LF, Bakris GL, Beckman JA, Bersin RM, Carr VF, Casey DE Jr, et al. $2010 \mathrm{ACCF} / \mathrm{AHA} / \mathrm{AATS} / \mathrm{ACR} / \mathrm{ASA} / \mathrm{SCA} / \mathrm{SCAI} / \mathrm{SIR} / \mathrm{STS} / \mathrm{SVM}$ guidelines for the diagnosis and management of patients with thoracic aortic disease: a report of the American College of Cardiology Foundation/American Heart Association Task Force on Practice Guidelines, American Association for Thoracic Surgery, American College of Radiology, American Stroke Association, Society of Cardiovascular Anesthesiologists, Society for Cardiovascular Angiography and Interventions, Society of Interventional Radiology, Society of Thoracic Surgeons, and Society for Vascular Medicine. Circulation. 2010;121:e266-369.

14. Coselli JS, LeMaire SA, Conklin LD, Adams GJ. Left heart bypass during descending thoracic aortic aneurysm repair does not reduce the incidence of paraplegia. Ann Thorac Surg. 2004;77:1298-303.
15. Crawford ES, Snyder DM, Cho GC, Roehm JO Jr. Progress in treatment of thoracoabdominal and abdominal aortic aneurysms involving celiac, superior mesenteric, and renal arteries. Ann Surg. 1978;188:404-22.

16. Kunihara T, Shiiya N, Wakasa S, Matsuzaki K, Matsui Y. Assessment of hepatosplanchnic pathophysiology during thoracoabdominal aortic aneurysm repair using visceral perfusion and shunt. Eur J Cardiothorac Surg. 2009; 35:677-83.

17. LeMaire SA, Jamison AL, Carter SA, Wen S, Alankar S, Coselli JS. Deployment of balloon expandable stents during open repair of thoracoabdominal aortic aneurysms: a new strategy for managing renal and mesenteric artery lesions. Eur $J$ Cardiothorac Surg. 2004;26:599-607.

18. Crawford ES. Thoraco-abdominal and abdominal aortic aneurysms involving renal, superior mesenteric, celiac arteries. Ann Surg. 1974;179:763-72.

19. Crawford ES, Rubio PA. Reappraisal of adjuncts to avoid ischemia in the treatment of aneurysms of descending thoracic aorta. J Thorac Cardiovasc Surg. 1973;66:693-704.

20. Patel R, Conrad MF, Paruchuri V, Kwolek CJ, Cambria RP. Balloon expandable stents facilitate right renal artery reconstruction during complex open aortic aneurysm repair. J Vasc Surg. 2010;51:310-5.

21. Clouse WD, Marone LK, Davison JK, Dorer DJ, Brewster DC, LaMuraglia GM, et al. Late aortic and graft-related events after thoracoabdominal aneurysm repair. J Vasc Surg. 2003;37:254-61. 